\title{
NUMERICAL FLOW MODELING AROUND OKINAWA FROM CORAL REEF AREA TO OPEN OCEAN
}

\author{
Yoshiaki Shiraki, ECOH Corporation, Japan, shiraki@ecoh.co.jp \\ Katsuyuki Suzuyama, ECOH Corporation, Japan, suzuyama@ecoh.co.jp \\ Hidenori Shibaki, ECOH Corporation, Japan, shibaki@ecoh.co.jp \\ Takashi Kuwae, Okinawa Prefecture, Japan, kuwaetk@pref.okinawa.lg.jp \\ Masaki Sakieda, Okinawa Prefecture, Japan, sakiedam@pref.okinawa.lg.jp
}

\section{INTRODUCTION}

Coastal area along the Okinawa sea is formed from coral reefs. In the area, coastal flows are generated by various factors of tide, wave, wind, river discharge and so on. In the offshore areas, oceanic currents including the Kuroshio also influence the coastal flows, because of the openness. Thus, the flow pattern becomes complicated by such external forces. To simulate the flow pattern of the Okinawa sea by numerical flow modeling, the model needs to deal with the various external forces from shallow coral reef area to deep open ocean. Additionally, steep slope exists in the offshore end of coral reef (see Fig.2). In such region, we have to be careful because flow simulation is likely unstable.

This study intends to develop the numerical flow model which is applicable to the Okinawa sea, and its performance has been tested in the several sea areas. In addition, field observations were carried out to investigate the flow phenomena and to verify the model accuracy. The result of filed observation and its comparing with the simulation is shown.

\section{FIELD OBSERVATION}

Field observations were carried out in several sea areas of coral reef, port and offshore area. The observations clarified the distributions and variations of water elevation and velocity around the fringing coral reef. In the offshore, the variations of oceanic current were observed. In the presentation, we will introduce some interesting phenomena obtained by the observations.

\section{NUMERICAL MODEL}

Figure 1 shows the framework of numerical model developed in this study. This model can calculate flow by various external forces, important in the area from coral reef to open ocean. The tidal elevations from NAOtide (Matsumoto el al., 2000) are set as the open boundary condition. The wave is simulated by SWAN (Simulating WAves Nearshore), and the radiation stress is given to the flow model. The distributions of wind and pressure are provided from GPV (Grid Point Value) by the Japan Meteorological Agency. The offshore conditions such as water elevation, velocity, water temperature and salinity are provided by JCOPE (Japan Coastal Ocean Predictability Experiment, Miyazawa and Yamagata, 2003), and also set as the open boundary condition. The hybrid vertical coordinate system (sigma and $\mathrm{z}$ ) is adopted as shown in Fig.2 so that the simulation is stable on steep slope and highly vertical resolution is maintained in shallow region by sigmacoordinate.

Figure 3 shows the distribution of horizontal velocity calculated by this flow model. It is found that the flow pattern of Okinawa sea from nearshore to offshore is simulated comprehensively. Figure 4 shows the time series of 25 hours moving averaged velocity by

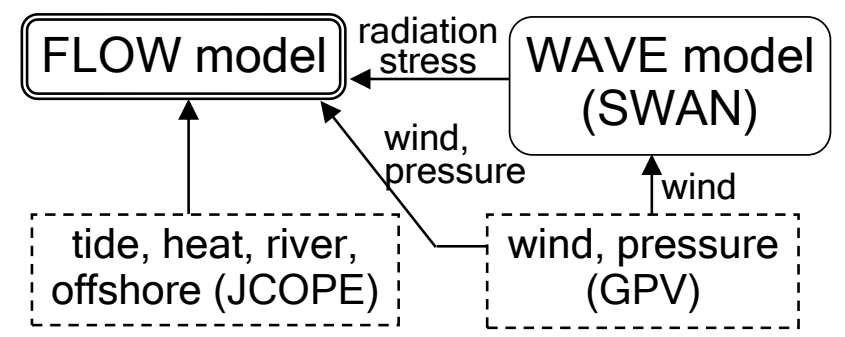

Figure 1 - Framework of flow model.

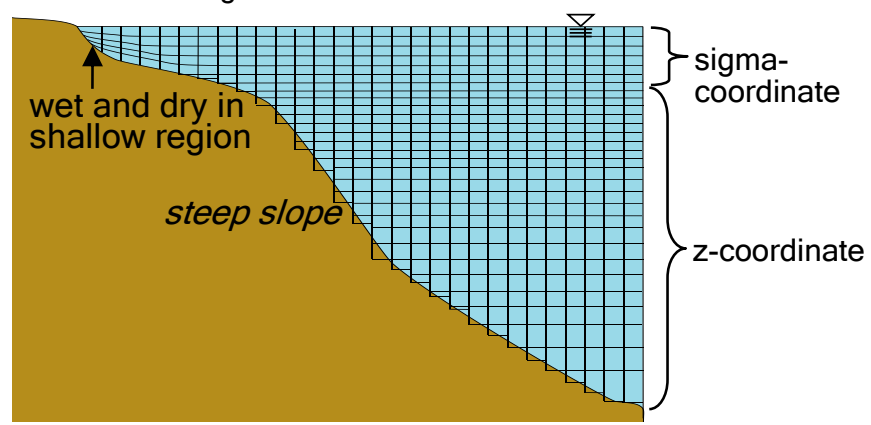

Figure 2 - Vertical coordinate system in flow model.
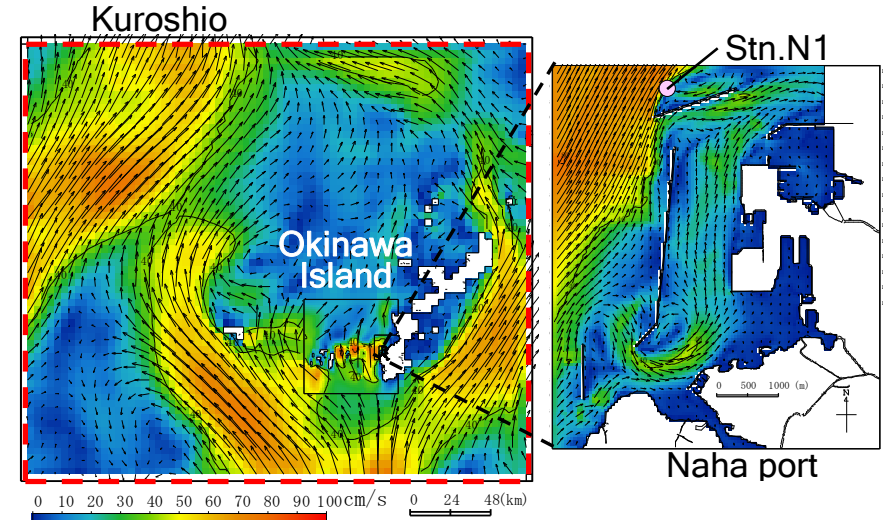

Figure 3 - Distribution of horizontal velocity around the Okinawa Island calculated by flow model (red broken line means open boundary).

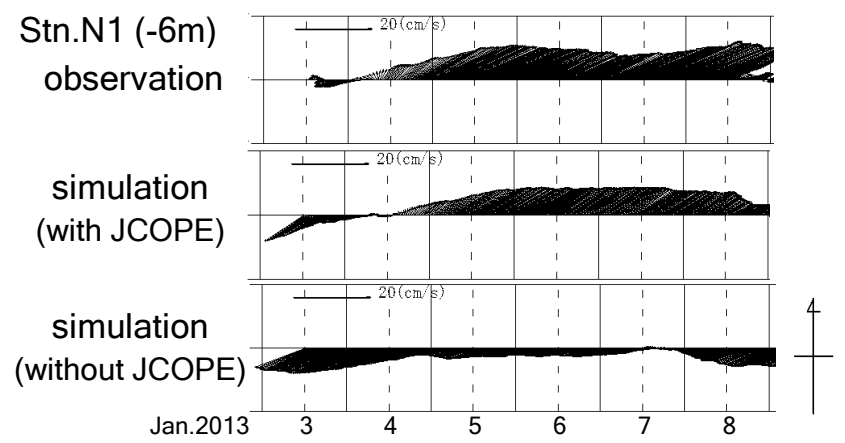

Figure 4 - Time series of 25 hours moving averaged velocity at Stn.N1 (shown in Fig.3). 
observation and simulation at Stn.N1 (location of Stn.N1 is shown in Fig.3). The observation shows that the northeastward mean flow exists during the period. In the simulation, 2 pattern simulations, "with JCOPE" and "without JCOPE", were carried out. In the case of "with JCOPE" which tide and oceanic current was given to the open boundary, the simulation reproduces the northeastward mean flow. On the other hand, in the case of "without JCOPE", i.e., without oceanic current, the mean flow cannot be reproduced. These results show that the oceanic condition may be important even in regions close to the shore.

As a simulation around the fringing coral reef, we introduce the example of Shiraho Coast which the water depth is shown in Fig.5. This area is divided into two areas, inside and outside, bordering the shallow region. The inside is high reef ridge, while the outside is relatively low reef ridge. Figure 6 shows the time series of water elevations of the inside (Stn.S2) and the outside (Stn.S1) by observation and simulation. While the tidal variation of Stn.S1 is consistent with that in the open ocean, that of Stn.S2 is asymmetric around the low tide. It is because that the reef ridges dry out and inner water is isolated so that the water level does not go down. Figure 6 shows that the simulation reproduces those variations of the water elevation inside and outside reefs.

Figure 7 shows the observed velocity by towing type ADCP (Acoustic Doppler Current Profiler). Tidal current exists along the reef edge. At the break of reef ridge, the reef current from inside to outside is observed as shown in Fig.7. Figure 8 shows the simulated velocity field at the same time as the ADCP observation in Fig.7. We can see that the simulation reproduces the current along the reef edge and the reef current at the break of reef ridge.

\section{CONCLUSION}

We developed the numerical flow model applicable to the complicated topography around Okinawa where shallow coral reefs and deep open ocean areas are adjacent. The flow model is able to deal with the various external forces, and simulate the flow pattern of those areas. Comparison between the simulation and observation showed the reproducibility of the model. As one of the useful tools, this model can contribute to environmental evaluation.

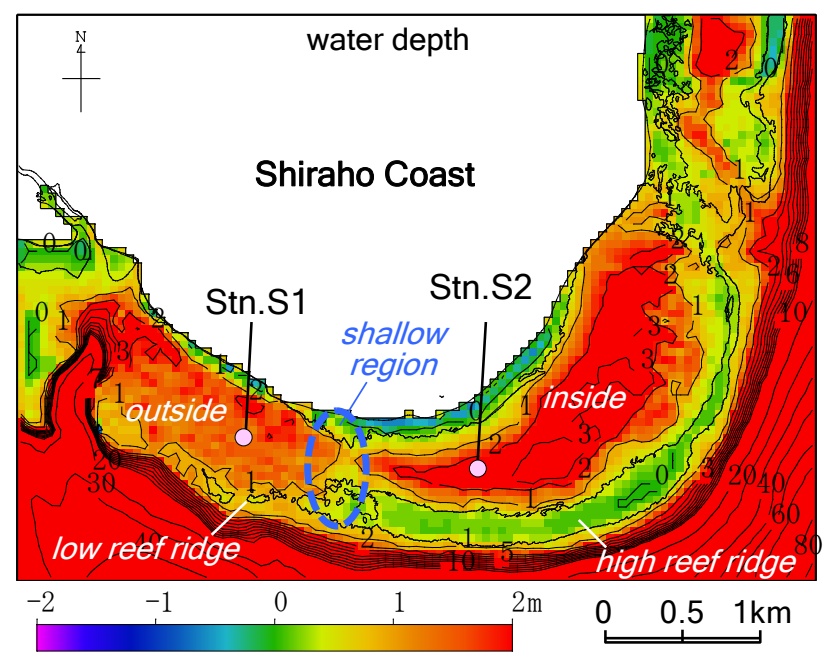

Figure 5 - Water depth around the Shiraho Coast (M.S.L).

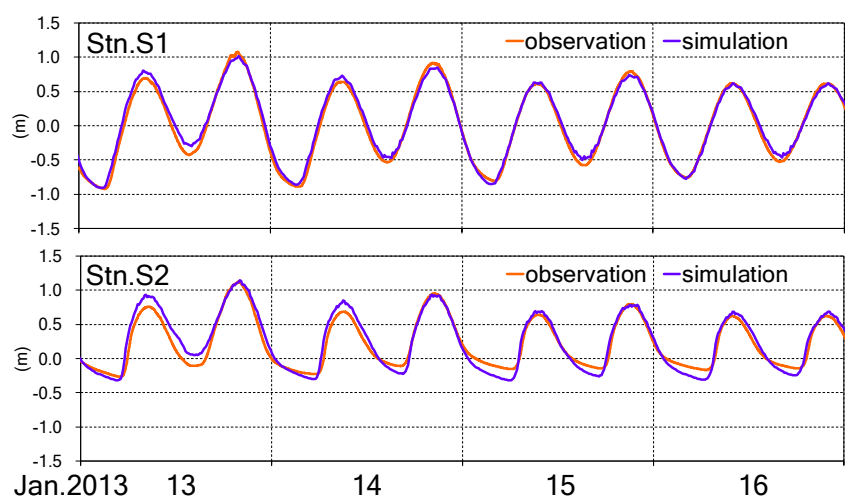

Figure 6 - Time series of water elevation by observation and simulation at Stn.S1 and S2 (shown in Fig.5).

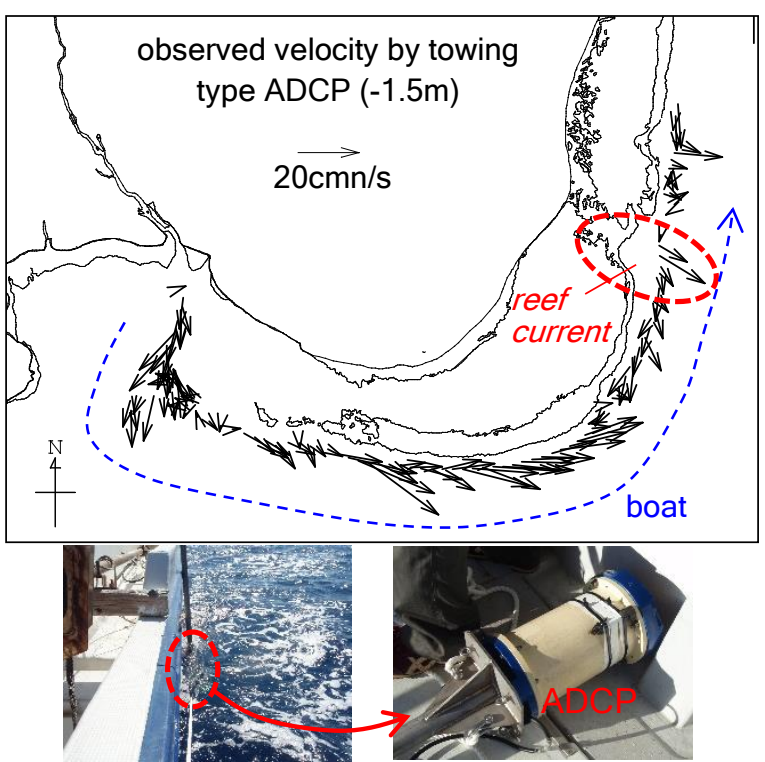

Figure 7 - Velocity fields by towing type ADCP observation.

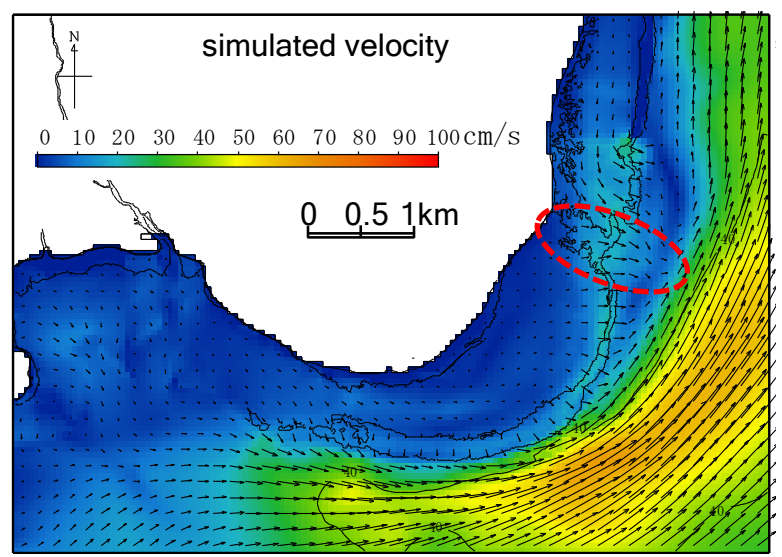

Figure 8 - Velocity field by simulation.

\section{REFERENCES}

Matsumoto, K., T. Takanezawa and M. Ooe: Ocean tide models developed by assimilating TOPEX/POSEIDON altimeter data into hydrodynamical model : A global model and a regional model around Japan, Journal of Oceanography, Vol.56, pp.567-581, 2000.

Miyazawa, Y. and T. Yamagata: The JCOPE ocean forecast system, First ARGO Science Workshop, November 12-14, 2003, Tokyo, Japan. http://www.jamstec.go.jp/jcope/ 